\title{
Saffron as an antidote or a protective agent against natural or chemical toxicities
}

\author{
Bibi Marjan Razavi ${ }^{1}$ and Hossein Hosseinzadeh ${ }^{2 *}$
}

\begin{abstract}
Saffron (Crocus sativus) is an extensively used food additive for its color and taste. Since ancient times this plant has been introduced as a marvelous medicine throughout the world. The wide spectrum of saffron pharmacological activities is related to its major constituents including crocin, crocetin and safranal. Based on several studies, saffron and its active ingredients have been used as an antioxidant, antiinflammatory and antinociceptive, antidepressant, antitussive, anticonvulsant, memory enhancer, hypotensive and anticancer. According to the literatures, saffron has remarkable therapeutic effects. The protective effects of saffron and its main constituents in different tissues including brain, heart, liver, kidney and lung have been reported against some toxic materials either natural or chemical toxins in animal studies.

In this review article, we have summarized different in vitro and animal studies in scientific databases which investigate the antidotal and protective effects of saffron and its major components against natural toxins and chemical-induced toxicities. Due to the lake of human studies, further investigations are required to ascertain the efficacy of saffron as an antidote or a protective agent in human intoxication.
\end{abstract}

Keywords: Saffron, Crocus sativus L, Crocin, Crocetin, Safranal, Antidote, Protective, Natural toxin, Chemical toxin

\section{Background}

Crocus sativus L., is a perennial herb which belongs to the Iridaceae family and is cultivated in Azerbaijan, France, Greece, India, Iran, Italy, Spain, China, Morocco, Turkey, Egypt, and Mexico [1]. Saffron, the dried stigma of the C. sativus, has been extensively used as a spice and food colorant because of its color and taste [2].

Saffron contains more than 150 chemicals agents [3]. Among which three main components of saffron are responsible for its pharmacological effects including: crocins, the principle coloring agent (mono and diglycosyl esters of a polyene dicarboxylic acid, named crocetin) [4], the glycoside picrocrocin which is a precursor of safranal and responsible for its bitter taste and safranal, a monoterpen aldehyde which is the deglycosylated form of picrocrocin and is responsible for the characteristic aroma of saffron $[5,6]$.

In folk medicine, saffron has been believed to have several properties such as antispasmodic, eupeptic,

\footnotetext{
* Correspondence: hosseinzadehh@mums.ac.ir

2Pharmaceutical Research Center, Department of Pharmacodynamy and Toxicology, School of Pharmacy, Mashhad University of Medical Sciences, Mashhad, Iran

Full list of author information is available at the end of the article
}

anticatarrhal, nerve sedative, carminative, diaphoretic, expectorant, stimulant, stomachic and aphrodisiac $[7,8]$. Moreover, modern pharmacological studies have demonstrated that saffron and its constituents have a wide spectrum of activities including antioxidant [9], anticonvulsant [10-12], antidepressants and anxiolytics [13-16], antinociceptive and anti-inflammatory $[17,18]$, memory enhancers [19-21], antitussive [22], reducing withdrawal syndrome [23], improving male erectile dysfunction [24], hypotensive [25-27], anticancer [28,29] and antisolar [30,31].

Furthermore according to the literature, the protective effects of saffron as well as its active components in different tissues including brain [32], heart [33], liver [34], kidney [35], lung [36] and etc have been reported against some toxic materials.

\section{Methods}

In this review article, we have discussed different studies in scientific databases including Scopus, MEDLINE and Web of Science databases and local references, which investigate the antidotal and protective effects of saffron 
and its major components against natural toxins and chemical-induced toxicity. Studies were identified through electronic databases from their inception up to October 2014. The keywords for the search were: Crocus sativus, saffron, crocin, safranal, crocetin, antidote, natural toxin, chemical toxin and protective effects.

\section{Natural toxins}

Documents have been shown saffron and its main components exhibit antidotal effects against some natural toxins including snake venoms [37], aflatoxins [38], lipopolysaccharides (LPS) [39] and 3-nitropropionic acid (3- NP) [40]. These effects might be due to their antioxidant [41], anti-inflammatory [37] and antiapoptotic [37] effects (Table 1).

\section{Snake venoms}

It is established that crocin could neutralize oxidative stress and hematological complications induced by viper venoms. The pre-incubation of crocin with venom (1:10; venom: crocin, $\mathrm{w} / \mathrm{w}$ ) at $37^{\circ} \mathrm{C}$ for $10 \mathrm{~min}$ ), suppressed the venom-induced oxidative stress, hematological alteration and pro inflammatory cytokine levels in Swiss albino male mice [41]. Furthermore, the inhibitory effect of crocin on viper venom-induced platelet and neutrophil apoptosis has been shown in other studies [37,42].
Crocin ameliorated the Vipera russelli venom-induced apoptotic events such as the generation of endogenous ROS, mobilization of intracellular calcium, depolarization of mitochondrial membrane, cytochrome c release, caspase activation, phosphatidylserine externalization and DNA damage $[37,42]$.

\section{Lipopolysaccharide (LPS)}

Based on the documents, saffron active constituents could suppress LPS-(endotoxin derived from gramnegative bacteria) induced mice lung injury [39], distributed intravascular coagulation in rabbits (DIC) [43] and LPS-stimulated RAW 264.7 macrophages [44].

Briefly, crocetin (50 and $100 \mathrm{mg} / \mathrm{kg}$, gavage) could reduce the LPS-induced lung edema and histological changes, increased LPS impaired SOD activity, and decreased lung MPO activity. Moreover, crocetin significantly attenuated LPS-induced mRNA and the protein expressions of IL-6, MCP-1, TNF- $\alpha$, phospho-IкB expression and NF-kB activity [39].

Another study revealed crocetin could improve DIC related haemostatic indices impaired by endotoxin including platelet blood counts, blood plasma fibrinogen and protein $\mathrm{C}$ concentration in rabbits [43].

In addition, in vitro studies showed that crocin suppressed the LPS-stimulated expression of iNOS by inducing

Table 1 Antidotal effects of saffron and its main constituents against natural toxins

\begin{tabular}{|c|c|c|c|c|}
\hline Toxin & In vitro/In vivo & Constituents & Results & Ref. NO \\
\hline Snake venom & Swiss albino male mice & Crocin & $\begin{array}{l}\text { Suppression of oxidative stress, hematological } \\
\text { alteration and pro inflammatory cytokine levels }\end{array}$ & {$[37]$} \\
\hline Snake venom & Isolated platelet & Crocin & $\begin{array}{l}\text { Inhibition of oxidative stress and platelet } \\
\text { apoptosis }\end{array}$ & [41] \\
\hline Snake venom & Isolated neutrophils & Crocin & $\begin{array}{l}\text { Inhibition of oxidative stress and neutrophil } \\
\text { apoptosis }\end{array}$ & [42] \\
\hline AflatoxinB1 & Male Wistar rats & Crocetin (0.1 mg/day/rat) & $\begin{array}{l}\text { Reduction of AST, ALT, AIP, and } y \text {-GGT, Elevation } \\
\text { of GSH, Reduction of the formation of hepatic } \\
\text { AFB }_{1} \text {-DNA adducts }\end{array}$ & {$[38]$} \\
\hline AflatoxinB1 & Female Sprague-Dawley rats & $\begin{array}{l}\text { Crocin dyes (50 mg/kg/day, } \\
3 \text { days) }\end{array}$ & Reduction of AST, ALT, AIP, $\gamma$-GGT and LDH & [47] \\
\hline Lipopolysaccharide & mice & $\begin{array}{l}\text { Crocetin ( } 50 \text { and } 100 \mathrm{mg} / \mathrm{kg} \\
\text { gavage) for } 24 \mathrm{hr}\end{array}$ & $\begin{array}{l}\text { Reduction of lung edema, Increase in SOD, } \\
\text { Decrease in MPO, Attenuation of mRNA and } \\
\text { protein expressions of IL-6, MCP-1, TNF-a, P-IKB } \\
\text { and NF-kB }\end{array}$ & [39] \\
\hline Lipopolysaccharide & RAW 264.7 macrophages & Crocin & $\begin{array}{l}\text { Suppression of iNOS induction of HO-1 expression } \\
\text { via Ca2+/calmodulin-CAMK4-PI3K/Akt-Nrf2 }\end{array}$ & [45] \\
\hline Lipopolysaccharide & Rabbit & Crocetin & $\begin{array}{l}\text { Improve of DIC-related haemostatic indices such } \\
\text { as platelet blood counts, blood plasma fibrinogen } \\
\text { and protein C concentration, Amelioration of } \\
\text { DIC-associated disease and fibrin deposition in } \\
\text { the glomeruli }\end{array}$ & [43] \\
\hline Lipopolysaccharide & RAW 264.7 macrophages & Crocin & $\begin{array}{l}\text { Inhibition of the PGE(2) products, Prevention of } \\
\text { NF-kappaB p50 and p65 subunits }\end{array}$ & [44] \\
\hline 3-nitropropionic acid & Isolated striatal synaptosomes & $\begin{array}{l}\text { Saffron extract }(1 \mathrm{mg} / \mathrm{kg} / \text { day, } \\
\text { for } 5 \text { days, IP.) }\end{array}$ & $\begin{array}{l}\text { Decrease of lipid peroxidation, Improve of } \\
\text { mitochondrial function }\end{array}$ & {$[40]$} \\
\hline
\end{tabular}


HO-1 expression via $\mathrm{Ca}^{2+} /$ calmodulin-dependent protein kinase 4 -PI3K/Akt-Nrf2 signaling cascades [45].

In another study, crocin inhibited the prostaglandin E2 products in LPS-stimulated RAW 264.7. Furthermore, crocin prevented the nuclear translocation of the NFkappa B p50 and p65 subunits [44].

\section{Mycotoxins}

\section{Aflatoxin B1 (AFB1)}

AFB1 is an aflatoxin produced by Aspergillus flavus and Aspergillus parasiticus [46]. Crocetin and crocin were found to possess protective effects against AFTB1 hapatotoxicity and AFTB1 DNA adducts via the reduction of hepatic injury markers (AST, ALT, ALP and $\gamma$-GGT) and elevations of hepatic glutathione (GSH) and activities of GST and GSH-Px in animal models [38,47].

\section{Nitropropionic acid (3-NPA)}

3-NPA is a fungal toxin which is known to affect mitochondria and subsequently leads to ATP depletion and causes neurotoxicity [40]. The protective effect of saffron extract in striatal synaptosomes isolated from the brain of rats exposed to the mitochondrial toxin 3-NPA has been reported. 3-NPA-(20 mg/kg/day, for 3 days, IP.), induced a significant increase in lipid peroxidation and decreased the mitochondrial function in synaptosomal fractions. However, saffron extract ( $1 \mathrm{mg} / \mathrm{kg} /$ day, for 5 days, IP.) decreased lipid peroxidation and improved mitochondrial function through antioxidant property [40].

\section{Chemical-induced toxicity \\ Protective effects of saffron against chemical-induced hepatotoxicity}

Based on the evidences from animal studies, saffron has ability to possess protective effects against hepatotoxicity induced by some materials including beryllium chloride ( $\mathrm{BeCl} 2)$ [48], aluminum chloride $(\mathrm{AlCl} 3)$ [49], carbon tetrachloride (CCl4) [50], acetaminophen [51], cyclophosphamide [52], diazinon (DZN) [34] and paraquate (PQ) [53] through modulation of antioxidant enzymes [49,52], improvement in structural liver damages [51], reduction in markers of hepatic injury such as AST, ALT, ALP, LDH, GGT, lipid and protein oxidation [48,50-52], alleviation of apoptosis [34], increase in GSH [48] and improvement in lipid dysregulation through ERK1/2 pathway [54].

\section{Metals}

Beryllium (Be) $\mathrm{BeCl} 2$ is a highly toxic material which accumulates in different tissues after absorption. Oral intake through drinking water is a common route of human exposure to Be. Furthermore, workers are exposed to Be containing dusts during the crushing and grinding of ores, and during the processing of Be metal and alloys [55].
It is documented that crocin $(200 \mathrm{mg} / \mathrm{kg}$, for 7 consecutive days with $\mathrm{BeCl} 2$ or 7 consecutive days before $\mathrm{BeCl} 2$, IP.), reduced $\mathrm{BeCl} 2-(86 \mathrm{mg} / \mathrm{kg}$, orally for 5 consecutive days) induced liver toxicity. The increase in MDA and LDH levels, decrease in GSH content and haematological parameters induced by $\mathrm{BeCl} 2$ were modulated by crocin [48].

\section{Aluminum (Al)}

Aluminum (Al) is the third most abundant element in nature [56]. It is a constituent of cooking utensils, medicines, deodorants, and food additives. The sources of $\mathrm{Al}$ include corn, yellow cheese, salt, herbs, spices, tea, cosmetics, cookwares, and containers [57].

Shati et al. (2010) revealed saffron and honey minimized the toxic effect of $\mathrm{AlCl}_{3}$ in the liver by alleviating its disruptive effect on the biochemical and molecular levels. A significant increase in the cholesterol levels, triglycerides, GGT, ALT, AST, ALP, lipid peroxidation, and glucose were observed in the $\mathrm{AlCl}_{3}$ group. However, co treatment of $\mathrm{AlCl}_{3}$ with saffron and honey improved the disrupted liver biochemical markers and alleviated the increase of lipid peroxidation [49].

\section{Acetaminophen}

Acetaminophen ( $\mathrm{N}$-acetyl-p-aminophenol) is a widely used drug as an analgesic and antipyretic (Ahmad, 2010). It is a known hepatotoxic in overdose [58]. Omidi et al. (2014) showed that $20 \mathrm{mg} / \mathrm{kg}$ of C. sativus petals hydroalcoholic extract ameliorated acetaminophen-induced acute liver injury in rats through reducing the levels of AST, ALT and bilirubin, and increased the total protein and albumin. Cell swelling, severe inflammation and necrosis were observed in acetaminophen exposed rats; however in saffron treated rats only mild hepatocyte degeneration was seen [51].

\section{Carbon tetrachloride (CCl4)}

$\mathrm{CCl} 4$ is a solvent which causes liver toxicity by many roots of administration (oral, inhalation, and parenteral exposures) [50]. It has been shown that CCl4-induced fatty degeneration and vacuole formation and increased the levels of ALT and AST in plasma. The aqueous and ethanolic extracts of $C$. sativus stigmas and petals significantly decreased these impairments [50].

\section{Cyclophosphamide}

Cyclophosphamide is an alkylating agent commonly used as a chemotherapeutic and immunosuppressive drug [59]. A study by Jnaneshwari et al. (2013) exhibited the protective efficacy of crocin against hepatotoxicity induced by cyclophosphamide in Wistar rats. Crocin $(10 \mathrm{mg} / \mathrm{kg}$ for 6 days, orally) after the administration of a single dose of cyclophosphamide (150 mg/kg, IP.), significantly improved 
hepatic and antioxidant enzymes, lipid and protein oxidation [52]. Another study showed crocetin significantly elevated GST activity both in the bladder and the liver of mice treated with cyclophosphamide [60].

\section{Pesticides}

Paraquat It was reported that paraquat (PQ $5 \mathrm{mM}$ ), a widely used herbicide, increased leakage of LDH and ALT in rat primary hepatocytes and crocetin (10, 20 $\mu \mathrm{M})$ significantly suppressed the hepatotoxicity [53].

Diazinon (DZN) DZN is an organophosphate insecticide. In addition to the acetyl cholinesterase inhibition, it can damage tissues via oxidative stress [61]. Lari et al. (2013) indicated that crocin reduced DZN-induced hepatotoxicity through suppression the increase in MDA and attenuation the activation of caspases and reduction the $\mathrm{Bax} / \mathrm{Bcl}-2$ ratio [34].

\section{Protective effects of saffron against chemical-induced cardiovascular toxicity}

The protective effects of saffron and its active constituents have been shown against DZN (an organophosphate insecticide) [33], doxorubicin (an antitumor agent) [62] and isoproterenol-(a synthetic non-selective $\beta$ adrenoceptor agonist) [63] induced cardiac toxicity in previous studies through several mechanisms including modulation of cardiac hemodynamic [63], histopathological and ultrastructural impairments [63], improvement in cardiac markers such as CK-MB [33,64], alleviation of lipid peroxidation [33], suppression of genes involved in cardiac apoptosis and anti-inflammatory effects [33].

\section{Diazinon (DZN)}

It was reported that $\mathrm{DZN}-(15 \mathrm{mg} / \mathrm{kg}$, gavage, for 28 days) induced vascular toxicity which may be due to oxidative stress and not to a cholinergic mechanism [65]. Crocin $(20 \mathrm{mg} / \mathrm{kg}$, IP., for 28 days) improved toxic effects of DZN via reducing lipid peroxidation and restoring altered contractile and relaxant responses in rat aorta [65]. In addition concurrent administration of crocin and DZN could restore the effects of subchronic DZN administration on systolic blood pressure and heart rate in rats [66]. Besides antioxidant effects, a research has been shown that crocin exhibited protective effects against DZN-induced mitochondrial-mediated apoptosis in heart tissue of rat following subchronic exposure [33] (Figure 1). Furthermore, it was reported the aqueous extract of $C$. sativus (saffron) stigma and its main components, crocin and safranal, prevented DZN-induced

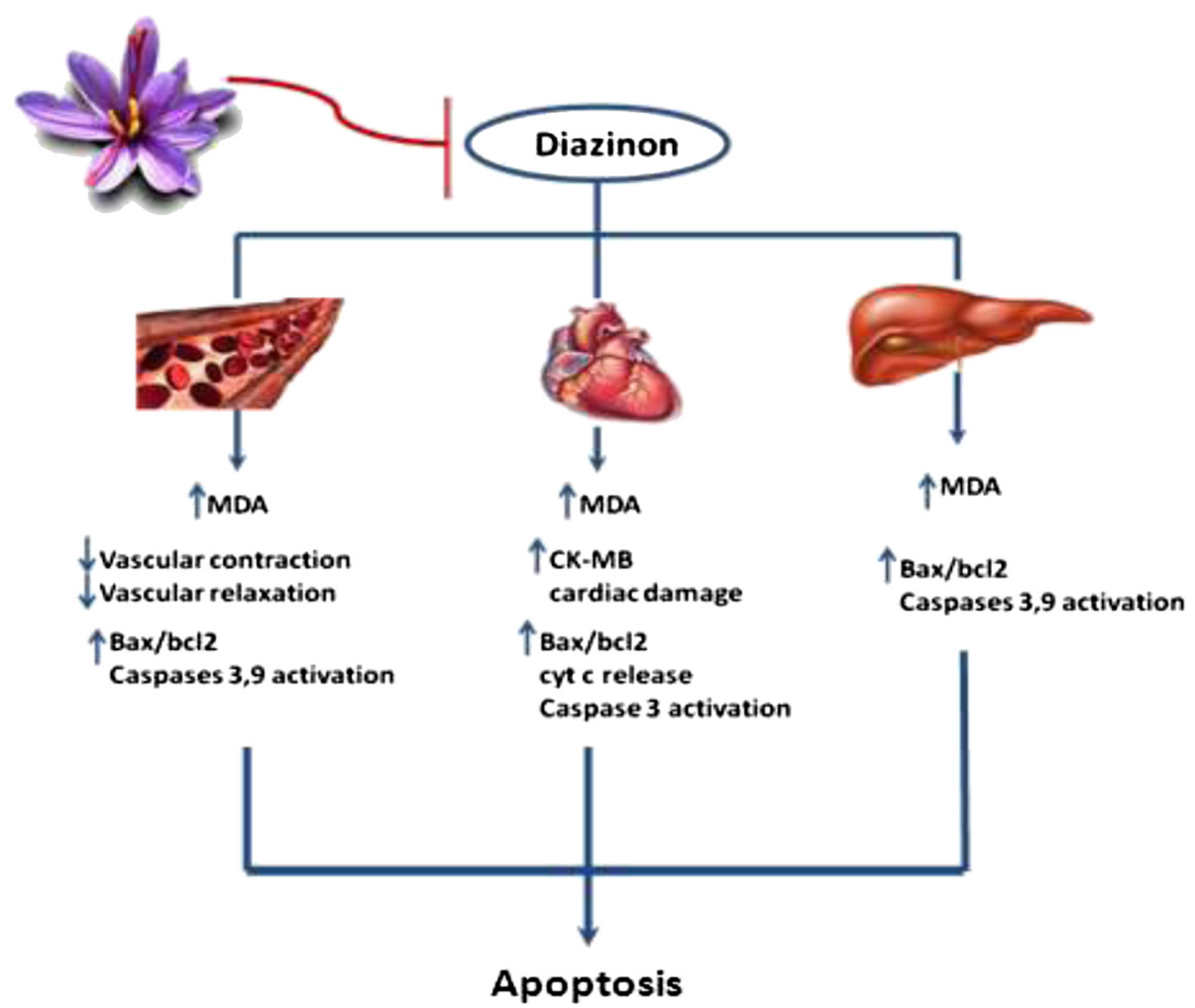

Figure 1 Schematic mechanistic description of saffron against toxicity induced by DZN. 
enzymes elevation and some specific biomarkers including, CK-MB, TNF-a, 8-iso-prostaglandin F2a and soluble protein-100 $\beta$ in rats $[67,68]$.

\section{Isoproterenol}

Mehdizadeh et al. (2013) demonstrated saffron or safranal could reduce histopathological damages as well as lipid peroxidation in rat heart tissues and also decreased CK-MB and LDH activities in serum induced by isoproterenol [64]. Similar study showed crocin $(20 \mathrm{mg} / \mathrm{kg} /$ day $)$ may have cardioprotective effects in isoproterenol-induced cardiac toxicity via modulation hemodynamic, antioxidant, histopathological and ultrastructural impairments [63].

\section{Doxorubicin}

Doxorubicin is an anthracycline antibiotic which is used as an antitumor agent [69]. It is well known that anthracyclines can induce cardiotoxicity by releasing ROS [62].

To evaluate the effect of saffron against acute myocardium injury by anthracyclines, the model of an isolated rabbit heart was used. ROS was generated by electrolysis of the perfused heart solution and/or generated by perfusion with $30 \mu \mathrm{M}$ doxorubicin in the presence and absence of $10 \mu \mathrm{g} / \mathrm{ml}$ saffron extracts. ROS generated by two models affects cardiovascular function; it decreased ventricular pressure, heart rate and coronary flow and increased lipid peroxidation while SOD activity decreased. The myocardial architecture was also altered by ROS. Saffron perfused during electrolysis could trap ROS and significantly improved myocardial function [62].

\section{Protective effects of saffron against chemical-induced genotoxicity \\ Antitumors}

It was proved saffron extract could protect against some antitumor agents including cisplatin [70,71], cyclophosphamide [70,71], mitomycin-C [70,71], and methyl methanesulfonate (MMS) [72] in animals via modulation of lipid peroxidation, antioxidants and detoxification systems [70]. Saffron $(20,40$ and $80 \mathrm{mg} / \mathrm{kg})$ was orally administered to mice for 5 days prior to these antitumor agents. A significant reduction in lipid peroxidation with an increase in the liver enzymatic (SOD, CAT, GST, GPx) and nonenzymatic antioxidants (GSH) were observed in saffron pretreated animals. Moreover saffron significantly inhibited antitumor drugs-induced cellular DNA damage (strand breaks) as revealed by decreased comet tail length, tail moment and DNA percentage in the tail [70,71].

Hosseinzadeh et al (2007 and 2008) reported the effect of aqueous extract of $C$. sativus stigmas, crocin and safranal on MMS-(120 mg/Kg, IP.) induced DNA damage in different mice organs using the comet assay. The MMS-induced DNA damage (increase in the \% tail DNA) $(80 \mathrm{mg} / \mathrm{Kg})$ was decreased in some tissues including kidney, lung and spleen in C. sativus stigmas aqueous extract, crocin and safranal pretreated mice [72,73].

\section{Paraquat (PQ)}

Crocetin also decreased genotoxicity induced by PQ. In this study oxyradical generated by PQ caused DNA damage which was evaluated with unscheduled DNA synthesis in rat primary hepatocytes [53].

\section{Protective effects of saffron against chemical-induced pulmonary toxicity \\ Benzo[a]pyrene}

Benzo[a]pyrene is a polycyclic aromatic hydrocarbon isolated from coal tar [36]. It can interact with lipids of membrane and consequently produces free radicals [36]. A study showed that single dose of benzo[a]pyrene $(100 \mathrm{mg} / \mathrm{kg}$, IP) could increase the level of ROS and lipid peroxides in lung mitochondria, and reduced the levels of membrane ATPase, GSH and lung mitochondrial enzymes in mice. Furthermore, the level of 8-Hydroxy-2-deoxyguanosine $(8-\mathrm{OHdG})$ in lung DNA of mice was induced by benzo[a]pyrene. Crocetin $(20 \mathrm{mg} / \mathrm{kg}$, IP.) protected the structural and functional impairment of lung mitochondria induced by benzo[a]pyrene following 18 weeks treatment (starting from 4th to 22nd week) after the first dose of benzo[a]pyrene [36].

\section{Protective effects of saffron against chemical-induced neurotoxicity \\ Aluminum}

Aluminum is the third most abundant element in nature [36]. It is an accepted neurotoxin implicated in the pathogenesis of neurodegenerative diseases [32]. Linardaki et al. (2013) reported $\mathrm{Al}$ intake $(50 \mathrm{mg} / \mathrm{kg} / \mathrm{day}$ in the drinking water for 5 weeks) could cause memory impairment, increase of brain MDA and reduction of GSH content, significant reduction of $\mathrm{AChE}$ and BuChE activity, activation of brain $\mathrm{MAO}$ isoforms and inhibition of cerebellar MAO-B in mice. Although co-administration with saffron extract $(60 \mathrm{mg} / \mathrm{kg} /$ day, for the last 6 days, IP.) had no effect on cognitive performance, it reversed significantly the $\mathrm{Al}$-induced changes in MAO activity and the levels of MDA and GSH.

Another study revealed $40 \mathrm{mg} / \mathrm{kg} /$ day of $\mathrm{A}_{1 C 1_{3}}$ for 90 days caused a decrease in the AChE activity and enzymatic antioxidant activities in both cerebral hemisphere and cerebellum of rats. Moreover, the expression of A Disintegrin and Metalloprotease, AChE, P53, Bcl-2 and interleukins (IL-4 and IL-12) genes in $\mathrm{AlCl}_{3}$ group was changed. Saffron aqueous extract $(200 \mathrm{mg} / \mathrm{kg} /$ day $)$ attenuated the neurotoxic effects of $\mathrm{AlCl}_{3}$ [74]. 


\section{Acrylamide (ACR)}

ACR, is an industrial potent neurotoxic agent in human and animals that has been recently found in carbohydrate rich foods cooked at high temperatures [75]. The effect of crocin, on ACR-induced cytotoxicity was evaluated using PC12 cells. The pretreatment of cells with $10-50 \mu \mathrm{M}$ crocin significantly attenuated ACR cytotoxicity in a dose-dependent manner. Crocin inhibited the down regulation of $\mathrm{Bcl}-2$ and the up regulation of $\mathrm{Bax}$ and decreased apoptosis in treated cells. Also, crocin inhibited ROS generation in cells exposed to ACR [76].

\section{Protective effects of saffron against chemical-induced nephro-or uro-toxicity Antitumors}

Cisplatin is an antitumor agent which induces nephrotoxicity via oxidative stress [77]. Naghizadeh et al. (2008) showed blood urea, creatinine, urinary glucose, protein concentrations and oxidative stress markers in crocin treated groups $(100,200$ and $400 \mathrm{mg} / \mathrm{kg}$, IP., for $4 \mathrm{con}$ secutive days ) were significantly lower than those of cisplatin $(5 \mathrm{mg} / \mathrm{kg})$. Cisplatin caused damage in S3 segment of proximal tubules, whereas no damage was observed in crocin treated rats [77].

Moreover, the administration of cysteine and vitamin E, C. sativus and Nigella sativa together with cisplatin partly reversed the kidney enzymes impairments induced by cisplatin [78].

Another study revealed crocetin $(50 \mathrm{mg} / \mathrm{kg})$ modulated the release of chloroacteldehyde, a urotoxic metabolite of cyclophosphamide in the urine of mice [60].

\section{Antibiotics}

The nephroprotective activity of saffron against gentamicin and ceftazidime-induced nephrotoxicity has been shown [79-81]. Gentamicin and/or ceftazidime caused histological changes as well as significant decrease in the body weights and urine output along with increase in protein and blood urea, serum creatinine, ESR, renal tissue levels of MDA and kidney weights in comparison with control rats. These changes were prevented by saffron [81].

\section{Hexachlorobutadiene}

Hexachlorobutadiene, is a potent nephrotoxic in rodents, which can cause degeneration, necrosis and regeneration in renal tubular epithelial cells [82]. Boroushaki et al. (2007) revealed that safranal $(0.25$ and $0.5 \mathrm{ml} / \mathrm{kg})$, has a protective effect against nephrotoxicity induced by hexachlorobutadiene in rats [82].

\section{Cadmium}

Cadmium (Cd) is an extremely toxic heavy metal used in industry. It is known to cause serious environmental and health effects including damage to renal and testis [83]. Asadi et al. (2014) showed that cadmium reduced sperm count, motility and vitality in comparison to control group. Saffron improved sperm parameters [84].

\section{Protective effects of saffron against chemical-induced hematological toxicity Diazinon (DZN)}

Hariri et al. (2011) showed that vitamin E, safranal (0.025 and $0.05 \mathrm{ml} / \mathrm{kg}$ ) and crocin $(50 \mathrm{mg} / \mathrm{kg}$ ) restored the reduction of red blood cells, hemoglobin and hematocrit induced by diazinon. These agents also prevented the reduction in platelets and the increase in reticulocytes. Vitamin E, crocin and safranal did not inhibit the effect of diazinon on RBC cholinesterase activity [85].

\section{Protective effects of saffron against chemical-induced embryo toxicity}

It is indicated that saffron aqueous extract $(200 \mathrm{mg} / \mathrm{kg}$ ) treated animals revealed improvement in maternal weight gain, embryolethality and bone ossification impaired by administration of $\mathrm{AlCL}_{3}(200 \mathrm{mg} / \mathrm{kg})$ during the embryogenesis (6th to 15th day of gestation) period [86]. Although saffron's usage in pregnancy can have some complication on the embryo. A study showed that high concentrations of the aqueous extract of saffron $(0.2 \%)$ can produce embryonic abnormalities [87]. Moreover Moallem et al. (2013) reported crocin or safranal can induce embryonic malformations when administered in pregnant mice as evidenced by decrease in length and weight of fetuses and induction of minor skeletal malformations, mandible and calvaria malformations, and growth retardation [68].

\section{Saffron as a protective agent against its constituent}

It was also shown that saffron could act as an antidote against its toxic constituent [88]. Safranal, the main component of $C$. sativus essential oil, is thought to be responsible for the unique odor of saffron $[5,6]$. Safranal has been shown protective effects against some drugand chemical- induced toxicity $[73,79,82,85]$. However, this constituent itself also exhibited side effects [89]. According to Iranian Traditional Medicine (ITM), the usage of whole plant may reduce some adverse effects induced by plant containing toxic ingredients [90]. A study by Ziaee et al (2014) showed that the aqueous extract of saffron stigma could reduce the toxicity of safranal [88]. It was found that the co-treatment of safranal and saffron significantly reduced the mortality rate induced by safranal and improved significantly all toxic effects of safranal on biochemical parameters in acute and subacute toxicities. Therefore, the consumption of saffron as a whole plant could be considered as a valuable method to reduce safranal toxicity [88]. 


\section{Conclusions}

In this review article, the different in vitro and animal studies summarized in order to discover the efficacy of saffron and its active constituents in protection against toxicities induced by natural or chemical toxins in different tissues.

According to the results of several important investigations, saffron and its active components act as an antidote in different intoxications induced by natural toxins including snakebites, mycotoxins and endotoxins.

Furthermore it is established saffron could act as an antidote for its constituent, safranal, which has more toxicity than the other constituents presented in saffron. Metals (Al, Be and cadmium), pesticides (DZN and PQ), acrylamide, benzo[a]pyrene and CCL4 are some examples of environmental and/or industrial chemical toxins which saffron could protect different tissues such as brain, cardiovascular, lung, kidney and liver against their toxicities. It is also documented this plant with wonderful power of therapeutic effects, exhibits protective effects against some chemical drugs such as antitumors (cisplatin, doxurobicin, cyclophosphamide and mitomycin), antibiotics (gentamycin and ceftazidime), analgesics (acetaminophen) which have organ toxicities especially in overdose. Some mechanisms including antioxidant, the modulation of cardiac, renal and liver enzymes, improvement in antioxidant defense systems, and the inhibition of apoptosis are involved in saffron antidotal effects.

In conclusion, based on the current review, saffron has an extensive spectrum of protective properties against toxicities induced by either natural or chemical toxins. As these findings have not yet been verified by clinical trials on humans, to establish the antidotal effects of saffron in human intoxications, human trials should be carried out.

\section{Abbreviations}

AST: Aspartate transaminase; ALT: Alanine transaminase; ALP: Alkaline phosphatase; $\gamma$-GGT: Gamma glutamyl transpeptidase; GST: Glutathione transpeptidase; GSH-Px: Glutathione peroxidase; LDH: Lactate dehydrogenase; CK-MB: Creatine kinase MB; ROS: Reactive oxygen species; SOD: Superoxide dismutase; CAT: Catalase; AChE: Acetylcholinesterase; BuChE: Butyrylcholinesterase; MAO: Monoamine oxidase; DIC: Disseminated intravascular coagulation; MPO: Myeloperoxidase; 3NPA: 3-Nitropropionic acid; IL-6: Interleukin-6; MCP-1: Macrophage chemo attractant protein-1; TNF-a: Tumor necrosis factor-a; iNOS: Inducible nitric oxide synthase; HO-1: Heme oxigenase-1.

\section{Competing interests}

The authors declare that they have no competing interests.

\section{Authors' contributions}

BR collected data and drafted the manuscript. $\mathrm{HH}$ gave the idea, designed and supervised the study, and edited the manuscript. Both authors read and approved the final manuscript.

\footnotetext{
Author details

${ }^{1}$ Targeted Drug Delivery Research Center, Department of Pharmacodynamy and Toxicology, School of Pharmacy, Mashhad University of Medical Sciences, Mashhad, Iran. ${ }^{2}$ Pharmaceutical Research Center, Department of Pharmacodynamy and Toxicology, School of Pharmacy, Mashhad University of Medical Sciences, Mashhad, Iran.
}

Received: 18 February 2015 Accepted: 20 April 2015

Published online: 01 May 2015

\section{References}

1. Xue X. Cultivation of Crocus sativus. Zhong Yao Tong Bao. 1982;7:3.

2. Winterhalter $P$, Straubinger M. Saffron-renewed interest in an ancient spice. Food Rev Int. 2000;16:39-59.

3. Bathaie SZ, Mousavi SZ. New applications and mechanisms of action of saffron and its important ingredients. Crit Rev Food Sci Nutr. 2010;50:761-86.

4. Alavizadeh $\mathrm{S}$, Hosseinzadeh H. Bioactivity assessment and toxicity of crocin: a Comprehensive Review. Food Chem Toxicol. 2014;64:65-80.

5. Abdullaev Fl. Biological effects of saffron. Biofactors. 1993;4:83-6.

6. Rezaee $\mathrm{R}$, Hosseinzadeh $\mathrm{H}$. Safranal: from an aromatic natural product to a rewarding pharmacological agent. Iran J Basic Med Sci. 2013;16:12-26.

7. Moghaddasi M. Saffron chemicals and medicine usage. J Med Plants Res. 2010;4:427-30

8. Hosseinzadeh $H$, Nassiri-Asl M. Avicenna's (Ibn sina) the canon of medicine and saffron (Crocus sativus): a review. Phytother Res. 2013;27:475-83.

9. Hosseinzadeh H, Shamsaie F, Mehri S. Antioxidant activity of aqueous and ethanolic extracts of Crocus sativus L. stigma and its bioactive constituents crocin and safranal. Pharmacogn Mag. 2010;5:419-24.

10. Hosseinzadeh $\mathrm{H}$, Khosravan $\mathrm{V}$. Anticonvulsant effects of aqueous and ethanolic extracts of Crocus sativus L. stigmas in mice. Arch Iran Med. 2002;5:44-7.

11. Hosseinzadeh $\mathrm{H}$, Talebzadeh F. Anticonvulsant evaluation of safranal and crocin from Crocus sativus in mice. Fitoterapia. 2005;76:722-4.

12. Hosseinzadeh $H$, Sadeghnia $H$. Protective effect of safranal on pentylenetetrazol-induced seizures in the rat: involvement of GABAergic and opioids systems. Phytomedicine. 2007;14:256-62.

13. Hosseinzadeh H, Karimi G, Niapoor M. Antidepressant effect of Crocus sativus L. stigma extracts and their constituents, crocin and safranal, in mice. J Med Plants. 2004;3:48-58.

14. Hosseinzadeh $H$, Noraei N. Anxiolytic and hypnotic effect of Crocus sativus aqueous extract and its constituents, crocin and saftanal, in mice. Phytother Res. 2009:26:768-74.

15. Ghasemi T, Abnous K, Vahdati F, Mehri S, Razavi BM, Hosseinzadeh $\mathrm{H}$. Antidepressant effect of Crocus sativus aqueous extract and its effect on CREB, BDNF, and VGF transcript and protein levels in Rat hippocampus. Drug Res. 2014, [Epub ahead of print].

16. Vahdati Hassani F, Naseri V, Razavi B, Mehri S, Abnous K, Hosseinzadeh H. Antidepressant effects of crocin and its effects on transcript and protein levels of CREB, BDNF, and VGF in rat hippocampus. Daru. 2014;8:22.

17. Hosseinzadeh $H_{1}$ Younesi MH. Antinociceptive and anti-inflammatory effects of Crocus sativus L. stigma and petal extracts in mice. BMC Pharmacol. 2002;2:7.

18. Hosseinzadeh $\mathrm{H}$, Shariaty VM. Anti-nociceptive effect of safranal, a constituent of Crocus sativus (saffron), in mice. Pharmacologyonline. 2007;2:498-503.

19. Abe K, Saito H. Effects of saffron extract and its constituent crocin on learning behaviour and long-term potentiation. Phytother Res. 2000;14:149-52.

20. Hosseinzadeh $\mathrm{H}$, Ziaei T. Effects of Crocus sativus stigma extract and its constituents, crocin and safranal, on intact memory and scopolamineinduced learning deficits in rats performing the Morris water maze task. J Med Plants. 2006:5:40-50+60.

21. Hosseinzadeh H, Sadeghnia H, Abbasi Ghaeni F, Motamedshariaty V, Mohajeri S. Effects of saffron (Crocus sativus L.) and its active constituent, crocin, on recognition and spatial memory after chronic cerebral hypoperfusion in rats. Phytother Res. 2012;10:1002.

22. Hosseinzadeh $\mathrm{H}$, Ghenaati J. Evaluation of the antitussive effect of stigma and petals of saffron (Crocus sativus) and its components, safranal and crocin in guinea pigs. Fitoterapia. 2006;77:446-8.

23. Hosseinzadeh H, Jahanian Z. Effect of Crocus sativus L. (saffron) stigma and its constituents, crocin and safranal, on morphine withdrawal syndrome in mice. Phytother Res. 2010;24:726-30.

24. Shamsa A, Hosseinzadeh H, Molaei M, Shakeri MT, Rajabi O. Evaluation of Crocus sativus L. (saffron) on male erectile dysfunction: a pilot study. Phytomedicine. 2009:16:690-3.

25. Imenshahidi $M$, Hosseinzadeh $H$, Javadpour $Y$. Hypotensive effect of aqueous saffron extract (Crocus sativus L.) and its constituents, safranal and crocin, in normotensive and hypertensive rats. Phytother Res. 2010;24:990-4.

26. Imenshahidi M, Razavi BM, Faal A, Gholampoor A, Mousavi SM, Hosseinzadeh H. The effect of chronic administration of saffron (Crocus sativus) stigma aqueous 
extract on systolic blood pressure in rats. Jundishapur J Nat Pharm Prod. 2013:8:175-9.

27. Imenshahidi M, Razavi BM, Faal A, Gholampoor A, Mousavi SM, Hosseinzadeh H. Effects of chronic crocin treatment on desoxycorticosterone acetate (doca)-salt hypertensive rats. Iran J Basic Med Sci. 2014;17:9-13.

28. Hosseinzadeh H, Behravan J, Ramezani M, Ajgan K. Anti-tumor and cytotoxic evaluation of Crocus sativus L. stigma and petal extracts using brine shrimp and potato disc assays. J Med Plants. 2005;4:59-65.

29. Aung HH, Wang CZ, Ni M, Fishbein A, Mehendale SR, Xie JT, et al. Crocin from Crocus sativus possesses significant anti-preliferation effects on human colorectal cancer cells. Exp Oncol. 2007;29:175-80.

30. Golmohammadzadeh S, Jaafari MR, Hosseinzadeh $H$. Does saffron have antisolar and moisturizing effects? Iran J Pharm Res. 2010;9:133-40.

31. Golmohammadzadeh S, Imani F, Hosseinzadeh H, Jaafari MR. Preparation, characterization and evaluation of sun protective and moisturizing effects of nanoliposomes containing safranal. Iran J Basic Med Sci. 2011;14:521-33.

32. Linardaki ZI, Orkoula MG, Kokkosis AG, Lamari FN, Margarity M. Investigation of the neuroprotective action of saffron (Crocus sativus L.) in aluminumexposed adult mice through behavioral and neurobiochemical assessment. Food Chem Toxicol. 2013;52:163-70.

33. Razavi B, Hosseinzadeh H, Movassaghi A, Imenshahidi M, Abnous K. Protective effect of crocin on diazinon induced cardiotoxicity in subcronic exposure. Chem boil inter. 2013;25:547-55.

34. Lari P, Abnous K, Imenshahidi M, Rashedinia M, Razavi M, Hosseinzadeh H. Evaluation of diazinon-induced hepatotoxicity and protective effects of crocin. Toxicol Ind Health. 2015;31:367-76.

35. Bandegi AR, Rashidypour A, Vafaei AA, Ghadrdoost A. Protective effects of Crocus Sativus L. extract and crocin against chronic-stress induced oxidative damage of brain, liver and kidneys in rats. Pharm Bull. 2014;4:493-9.

36. Venkatraman M, Konga D, Peramaiyan R, Ganapathy E, Dhanapal S. Reduction of mitochondrial oxidative damage and improved mitochondrial efficiency by administration of crocetin against benzo[a]pyrene induced experimental animals. Biol Pharm Bull. 2008;31:1639-45.

37. Santhosh MS, Thushara RM, Hemshekhar M, Sunitha K, Devaraja S, Kemparaju K, et al. Alleviation of viper venom induced platelet apoptosis by crocin (Crocus sativus): implications for thrombocytopenia in viper bites. J Thromb Thrombolysis. 2013; 1-9.

38. Lin JK, Wang CJ. Protection of crocin dyes on the acute hepatic damage induced by aflatoxin B1 and dimethylnitrosamine in rats. Carcinogenesis. 1986;7:595-9.

39. Yang $R$, Yang $L$, Shen $X$, Cheng W, Zhao B, Hamid Ali $K$, et al. Suppression of NF-kB pathway by crocetin contributes to attenuation of lipopolysaccharide-induced acute lung injury in mice. Eur J Pharmacol. 2012;674:391-6.

40. Urrutia EC, Riverón-Negrete L, Abdullaev F, Del-Angel DS, Martínez NLH, Cruz MEG, et al. Saffron extract ameliorates oxidative damage and mitochondrial dysfunction in the rat brain. Acta Hortic. 2007;739:359-66.

41. Santhosh SM, Hemshekhar M, Thushara RM, Devaraja S, Kemparaju K, Girish KS. Vipera russelli venom-induced oxidative stress and hematological alterations: amelioration by crocin a dietary colorant. Cell Biochem Function. 2013:31:41-50.

42. Santhosh MS, Sundaram MS, Sunitha K, Jnaneshwari S, Devaraja S, Kemparaju K, et al. Propensity of crocin to offset Vipera russelli venom induced oxidative stress mediated neutrophil apoptosis: a biochemical insight. Cytotechnology. 2014, [Epub ahead of print].

43. Tsantarliotou MP, Markala D, Kazakos G, Sapanidou V, Lavrentiadou S, Zervos I, et al. Crocetin administration ameliorates endotoxin-induced disseminated intravascular coagulation in rabbits. Blood Coagul Fibrinolysis. 2013;24:305-10.

44. Xu GL, Li G, Ma HP, Zhong H, Liu F, Ao GZ. Preventive effect of crocin in inflamed animals and in LPS-challenged RAW 264.7 cells. J Agric Food Chem. 2009:57:8325-30.

45. Kim JH, Park GY, Bang SY, Park SY, Bae SK, Kim Y. Crocin suppresses LPS-stimulated expression of inducible nitric Oxide synthase by upregulation of heme oxygenase-1 via calcium/calmodulin-dependent protein kinase 4. Mediators Inflamm. 2014;2014:728709.

46. Koehler P, Hanlin R, Beraha L. Production of aflatoxins B1 and G1 by Aspergillus flavus and Aspergillus parasiticus isolated from market pecans. Appl microbiol. 1975;30:581-3.

47. Wang CJ, Shiow SJ, Lin JK. Effects of crocetin on the hepatotoxicity and hepatic DNA binding of aflatoxin B1 in rats. Carcinogenesis. 1991;12:459-62.
48. El-Beshbishy HA, Hassan MH, Aly H, Doghish A, Alghaithy A. Crocin "saffron"protects against beryllium chloride toxicity in rats through diminution of oxidative stress and enhancing gene expression of antioxidant enzymes. Ecotoxicol Env Safety. 2012;83:47-54.

49. Shati A, Alamri S. Role of saffron (Crocus sativus L.) and honey syrup on aluminium induced hepatotoxicity. Saudi Med J. 2010;31:1106-13.

50. Iranshahi M, Khoshangosht M, Mohammadkhani Z, Karimi G. Protective effects of aqueous and ethanolic of saffron stigma and petal on liver toxicity induced by carbon tetrachloride in mice. Pharmacologyonline. 2011;1:203-12.

51. Omidi A, Riahinia N, Montazer Torbati M, Behdani M. Hepatoprotective effect of Crocus sativus (saffron) petals extract against acetaminophen toxicity in male Wistar rats. Avicenna J Phytome. 2014;4:330-6.

52. Inaneshwaria S, Hemshekhara M, Santhosha S, Sunithaa K, Thusharaa R, Thirunavukkarasub C, et al. Crocin, a dietary colorant mitigates cyclophosphamide-induced organ toxicity by modulating antioxidant status and inflammatory cytokines. J Pharm Pharmacol. 2013;65:604-14.

53. Tseng TH, Chu CY, Huang JM, Shiow SJ, Wang CJ. Crocetin protects against oxidative damage in rat primary hepatocytes. Cancer Lett. 1995;97:61-7.

54. Lari $P$, Rashedinia M, Abnous K, Hosseinzadeh H. Crocin improves lipid dysregulation in subacute diazinon exposure through ERK1/2 pathway in rat liver. Drug Res. 2014;64:301-5.

55. Deubner DC, Lowney YW, Paustenbach DJ, Warmerdam J. Contribution of incidental exposure pathways to total beryllium exposure. ApplOccup Environ Hyg. 2011;16:568-78.

56. Verstraeten SV, Aimo L, Oteiza PI. Aluminium and lead: molecular mechanisms of brain toxicity. Arch Toxicol. 2008;82:789-802.

57. Yokel R. The toxicology of aluminum in the brain: a review. Neurotoxicology. 2000;21:813-28.

58. Larson A, Polson J, Fontana R. Acetaminophen-induced acute liver failure: results of a united states multicenter, prospective study. Hepatology. 2005;42:1364-72

59. Huttunen K, Raunio H, Rautio J. Prodrugs-from serendipity to rational design. Pharmacol Rev. 2011;63:750-71.

60. Nair SC, Panikkar KR, Parthod RK. Protective effects of crocetin on the bladder toxicity induced by cyclophosphamide. Cancer Biother. 1993;8:339-44.

61. Akturk O, Demirin H, Sutcu R, Yilmaz N, Koylu H, Altuntas I. The effects of diazinon on lipid peroxidation and antioxidant enzymes in rat heart and ameliorating role of vitamin E and vitamin C. Cell Biol Toxicol. 2006;22:455-61.

62. Chahine N, Hanna J, Makhlouf H, Duca L, Martiny L, Chahine R. Protective effect of saffron extract against doxorubicin cardiotoxicity in isolated rabbit heart. Pharm Biol. 2013;51:1564-71.

63. Goyal SN, Arora S, Sharma AK, Joshi S, Ray R, Bhatia J, et al. Preventive effect of crocin of Crocus sativus on hemodynamic, biochemical, histopathological and ultrastuctural alterations in isoproterenol-induced cardiotoxicity in rats. Phytomedicine. 2010;17:227-32.

64. Mehdizadeh R, Parizadeh M-R, Khooei A-R, Mehri S, Hosseinzadeh H. Cardioprotective effect of saffron extract and safranal in isoproterenol-induced myocardial infarction in wistar rats. Iran J Basic Med Sci. 2013;16:56-63.

65. Razavi B, Hosseinzadeh H, Abnous K, Imenshahidi M. Protective effect of crocin on diazinon induced vascular toxicity in subchronic exposure in rat aorta ex-vivo. Drug Chem Toxicol. 2014;37:378-830.

66. Razavi M, Hosseinzadeh $\mathrm{H}$, Abnous K, Motamedshariaty V, Imenshahidi M. Crocin restores hypotensive effect of subchronic administration of diazinon in rats. Iran J Basic Med Sci. 2013;16:64-72.

67. Hariri A, Moallem S, Mahmoudi M, Memar B, Hosseinzadeh H. Sub-acute effects of diazinon on biochemical indices and specific biomarkers in rats: protective effects of crocin and safranal. Food Chem Toxicol. 2010;48:2803-8.

68. Moallem S, Afshar M, Etemad L, Razavi B,Hosseinzadeh H. Evaluation of teratogenic effects of crocin and safranal, active ingredients of saffron, in mice. Toxicol Ind Health. 2013, [Epub ahead of print]

69. Tacar O, Sriamornsak P, Dass C. Doxorubicin: an update on anticancer molecular action, toxicity and novel drug delivery systems. J Pharm Pharmacol. 2013;65:157-70.

70. Premkumar K, Abraham SK, Santhiya ST, Ramesh A. Protective effects of saffron (Crocus sativus Linn.) on genotoxins-induced oxidative stress in Swiss albino mice. Phytother Res. 2003;17:614-7.

71. Premkumar K, Thirunavukkarasu C, Abraham SK, Santhiya ST, Ramesh A. Protective effect of saffron (Crocus sativus L.) aqueous extract against genetic damage induced by anti-tumor agents in mice. Human Exp Toxicol. 2006;25:79-84 
72. Hosseinzadeh $H$, Abootorabi A, Sadeghnia HR. Protective effect of Crocus sativus stigma extract and crocin (trans-crocin 4) on methyl methanesulfonateinduced DNA damage in mice organs. DNA Cell Biol. 2008;27:657-64.

73. Hosseinzadeh $\mathrm{H}$, Sadeghnia HR. Effect of safranal, a constituent of Crocus sativus (saffron), on methyl methanesulfonate (MMS)-induced DNA damage in mouse organs: an alkaline single-cell gel electrophoresis (comet) assay. DNA Cell Biol. 2007;26:841-6.

74. Elsaid FG, Shati AA, Hafez EE. The protective role of coffea arabica L. and crocus sativus $L$. against the neurotoxicity induced by chronic administration of aluminium chloride. J Pharmacol Toxicol. 2011;6:647-63.

75. Manna F, Abdel-Wahhab M, Ahmed H, Park M. Protective role for Panax ginseng extract standardized with ginsenoside Rg3 against acrylamide induced neurotoxicity in rats. J Appl Toxicol. 2006;26:198-206.

76. Mehri S, Abnous K, Mousavi S, Motamed Shariaty V, Hosseinzadeh H. Neuroprotective effect of crocin on acrylamide-induced cytotoxicity in PC12 cells. Cell Mol Neurobiol. 2012;32:227-35.

77. Naghizadeh B, Boroushaki MT, Mashhadian NV, Mansouri SMT. Protective effects of crocin against cisplatin-induced acute renal failure and oxidative stress in rats. Iran Biomed J. 2008;12:93-100.

78. El Daly ES. Protective effect of cysteine and vitamin E, Crocus sativus and Nigella sativa extracts on cisplatin-induced toxicity in rats. J Pharm Belg. 1998:53:85-93.

79. Boroushaki MT, Sadeghnia HR. Protective effect of safranal against gentamicin-induced nephrotoxicity in rat. Iran J Med Sci. 2009;34:285-8.

80. Ajami M, Eghtesadi S, Pazoki-toroudi HR, Habibey R, Ebrahimi SA. Effect of crocus sativus on gentamicin induced nephrotoxicity. Biol Res. 2010;43:83-90,

81. Dhar MH, Shah KU, Ghongane BB, RANE SR. Nephroprotective activity of crocus sativus extract against gentamicin and/or ceftazidime - Induced nephrotoxicity in rats. Inter J Pharm Bio Sci. 2013;4:864-P70.

82. Boroushaki MT, Mofidpour H, Sadeghnia H. Protective effect of safranal against hexachlorobutadiene-induced nephrotoxicity in rat. Iran J Med Sci. 2007:32:173-6.

83. Nolan C, Shaikh Z. An evaluation of tissue metallothionein and genetic resistance to cadmium toxicity in mice. Toxicol Appl Pharmacol. 1986:85:135-44.

84. Asadi MH, Zafari F, Sarveazad A, Abbasi M, Safa M, Koruji M, et al. Saffron improves epididymal sperm parameters in rats exposed to cadmium. Nephro-Urol Month. 2014;6:e12125.

85. Hariri A, Moallem S, Mahmoudi M, Hosseinzadeh $\mathrm{H}$. The effect of crocin and safranal, constituents of saffron, against subacute effect of diazinon on hematological and genotoxicity indices in rats. Phytomedicine. 2011;18:499-504.

86. Hussein $\mathrm{HH}$, Mahmoud OM. Effects of maternal administration of aluminum chloride on the development of the skeletal system of albino rat fetuses protective role of saffron. Eur J Anat. 2013;17:63-71.

87. Tafazoli M, Kermani T, Saadatjoo A. Effects of saffron on abortion and its side effects on mice balb/c. OFOGH-E-DANESH. 2004:10:53-6.

88. Ziaee T, Razavi B, Hosseinzadeh $\mathrm{H}$. Saffron reduced toxic effects of its constituent, safranal, in acute and subacute toxicities in rats. Jundishapur J Nat Pharm Prod. 2014;9:3-8.

89. Hosseinzadeh H, Sadeghi Shakib S, Khadem Sameni A, Taghiabadi E. Acute and subacute toxicity of safranal, a constituent of saffron, in mice and rats. Iran J Pharm Res. 2013;12:93-9.

90. Mirheydar H. Herbal information: application of herbs in prevention and treatment of deseases. Tehran, IR (Iran): Islamic culture press centre; 2001.

\section{Submit your next manuscript to BioMed Central and take full advantage of:}

- Convenient online submission

- Thorough peer review

- No space constraints or color figure charges

- Immediate publication on acceptance

- Inclusion in PubMed, CAS, Scopus and Google Scholar

- Research which is freely available for redistribution 